\title{
COVID-19: ANTIVIRAL TEDAVi
}

\section{COVID-19: ANTIVIRAL TREATMENT}

\author{
Gülruhsar YILMAZ ${ }^{1}$ \\ ${ }^{1}$ Süleyman Demirel Üniversitesi Tıp Fakültesi Enfeksiyon Hastalıkları ve Klinik Mikrobiyoloji Anabilim Dalı \\ Cite this article as: YIImaz G. COVID-19: Antiviral Treatment. Med J SDU 2021; (ozelsayi-1):79-85.
}

\section{Öz}

Aralık 2020'de Çin'in Wuhan eyaletinde bildirilen vakalar birkaç ay içinde tüm dünyaya yayılmış ve 11 Mart 2020'de Dünya Sağlık Örgütü (DSÖ) tarafından SARS-CoV-2 enfeksiyonu pandemisi ilan edilmiştir. İlk vakaların görülmeye başlanmasından itibaren klinik pratikte kullanılan bazı ilaçlar yeniden konumlandırılarak COVID-19 tedavisinde kullanılmaya başlanmıştır. Konuyla ilgili çok sayıda makale hakem değerlendirmesi olmadan yayınlanmış, ciddi bir bilgi kirliliği ortaya çıkmıştır. Dünyada pandemi ilan edildiği tarih itibariyle ülkemizde de ilk koronavirüs enfeksiyonu olan hasta bildirilmiştir. Ülkemizde Sağlık Bakanlığı COVID-19 Rehberi doğrultusunda yeniden konumlandırılan ajanlar antiviral etki amacıyla tedavide kullanılmıştır. Hidroksiklorokin, favipiravir ve remdesivir kullanılan antiviral ajanlardır. Son zamanlarda monoklonal antikorlar klinik pratikte yer almaya başlamıştır. Bu yazıda SARS-CoV-2 enfeksiyonunun antiviral tedavisinde pandemi sürecinde kullanılan ilaçlar gözden geçirilmiştir.

Anahtar Kelimeler: COVID-19, antiviral, tedavi

\section{Abstract}

The cases reported in Wuhan province in China in December 2020 spread all over the world within a few months, and the SARS-CoV-2 infection pandemic was declared by the World Health Organization (WHO) on March 11, 2020. Since the first cases were seen, some drugs used in clinical practice have been repurposed and started to be used in the treatment of COVID-19. Many articles on the subject have been published without peer review, and a serious information pollution has emerged. As of the date the pandemic was declared in the world, the first patient with coronavirus infection was reported in our country. Repurposed agents like hydroxychloroquine, favipiravir and remdesivir have been used in treatment for antiviral effects in accordance with the Ministry of Health's COVID-19 Guideline and international literature in our country. Recently, monoclonal antibodies have started to take place in clinical practice. In this article, the drugs used in the antiviral treatment of SARS-CoV-2 infection during the pandemic process are reviewed.

Keywords: COVID-19, antiviral, therapy

\section{Giriş}

Aralık 2020'de Çin'in Wuhan eyaletinde bildirilen vakalar birkaç ay içinde tüm dünyaya yayılmış ve 11 Mart 2020'de Dünya Sağlık Örgütü (DSÖ) tarafından SARS-CoV-2 enfeksiyonu pandemisi ilan edilmiştir. İlk vakaların görülmeye başlanmasından itibaren klinik pratikte kullanılan bazı ilaçlar yeniden konumlandırılarak COVID-19 tedavisinde kullanılmaya başlanmıştır (1). Dünyada pandemi ilan edildiği tarih itibariyle ülkemizde de ilk koronavirüs enfeksiyonu olan hasta bildirilmiştir. Ülkemizde Sağlık Bakanlığı Koronavirüs Rehberi ve literatür doğrultusunda yeniden konumlandırılan ajanlar antiviral etki amacıyla tedavide kulla- 
nılmıștır (2). Bu yazıda SARS-CoV-2 enfeksiyonunun antiviral tedavisinde pandemi sürecinde kullanılan ilaçlar gözden geçirilmiştir.

COVID-19 enfeksiyonunun tedavisinde hastalığın dönemi, kullanılan ajanlar açısından belirleyici olmaktadır. Hastalıkta evreleri kesin sınırlarla ayırmak mümkün olmamakla birlikte 1 . evre 7 . güne kadar olan dönem olup erken enfeksiyon evresi, 2. evre 8-14. günler arasında pulmoner faz evresi, 3. evre 14. günden sonra ve hiperinflamasyon fazı olarak tanımlanmıştır (3). Erken enfeksiyon evresi antiviral tedavilerin en etkili olacağı dönemdir.

Pandemi sürecinde çok sayıda yeniden konumlandırıIan ilaç antiviral amaçla kullanılmıştır. Bunlar, virüsün hücreye giriş ve replikasyon fazına etkili olabileceği düşünülen ajanlardır (1).

\section{Hidroksiklorokin}

Hidroksiklorokin (HQ) in vitro çalışmalarda SARSCoV-2'yi inhibe ettiği rapor edilen normal koşullarda sıtma tedavisinde kullanılan bir ajandır (4-8). Proteaz enzimine afinite, asidik ortamları bazik hale çevirerek replikasyonun inhibe edilmesi ve sitokin salınımını engelleyebileceği hipotezi etki mekanizmaları olarak bildirilmiştir $(7,9,10)$. SARS-CoV-2'nin hücre içine girişinde ACE-2 ve TMPRSS2 reseptörlerinin aracılık ettiği gösterilmiştir. Hidroksiklorokinin TMPRSS2 varlığında virüsün hücre içine girişini engelleyemediği daha sonra yapılan çalışmalarda rapor edilmiş, insanda akciğer hücrelerinde TMPRSS2 reseptörleri bulunduğundan ilacın etkinliği ile ilgili soru işaretleri gündeme gelmiştir $(11,12)$. Maisonnasse ve arkadaşları tarafından makaklarda yapılan bir çalışmada HQ'nun SARS-CoV-2 enfeksiyonunda doz, kullanıldığı dönem, azitromisinle kombine kullanımdan bağımsIz olarak viral klirens, radyolojik düzelme ve klinik iyileşme üzerine herhangi bir etkisinin olmadığı saptanmıştır (12).

Klinik çalışmalar sonlanıncaya dek olan süreçte Amerika Gıda ve illaç Kurumu (FDA) tarafından HQ kullanımına acil onay verilmiş, HQ ülkelerin bir kısmında klinik çalışmalar kapsamında bir kısmında rutin olarak SARS-CoV-2 infeksiyonu profilaksisi ve tedavisinde kullanılmıştır (13).

Oral yolla kullanıldığında HQ'nun biyoyararlanımı \%80 civarındadır $(14,15)$. Çalışmalarda farklı dozlarda kullanılmıştır. Yao ve arkadaşlarının önerdiği doz ilk gün 2 × 400 mg yükleme takiben $2 \times 200$ mg idame şeklindedir (7). Ülkemiz de dahil çoğu yerde bu dozlarda kullanılmıştır. Böbrek ve karaciğer yetmezliğinde doz ayarlaması ile ilgili yeterli veri bulun- mamaktadır. İstenmeyen etkileri değerlendirildiğinde en önemlisi QT aralığında uzamaya neden olmasıdır (14). Bir diğer yan etkisi retinal toksisite olarak bildirilmiştir $(9,16)$. Miyopati, rabdomiyoliz, mide bulantısı, ishal ve karaciğer fonksiyon bozukluğu bildirilen diğer istenmeyen etkilerdir (17).

Hidroksiklorokinin etkinliğini değerlendiren iki büyük çalışmadan ilki "Randomized Evaluation of COVID-19 Therapy (RECOVERY)" çalışmasıdır. Bu çalışmada primer sonlanım noktası 28. gün mortalitesi olarak belirlenmiştir. Çalışmanın sonuçlarına göre mortalite HQ alan grupta \%27 kontrol grubunda \%25 olarak bulunmuştur $(p=0.15)(18)$. İkinci çalışma Dünya Sağlık Örgütü (DSÖ) tarafından yürütülen Solidarity olup 30 ülkeden 450 hastane bu çalışmaya katılmıştır. Bu çaIışmada da HQ uygulanan grup ile kontrol grubu arasında mortalitenin farklı olmadığı bildirilmiştir $(p=0.23)$ (19). Sonuçta RECOVERY çalışmasında Haziran 2020, Solidarity çalışmasında Temmuz 2020 itibariyle HQ tedavi koluna hasta alımı durdurulmuştur. Hidroksiklorokinin oksijen ihtiyacı, mortalite, mekanik ventilatör (MV) intiyacı, viral klirens, klinik iyileşme ve hastanede kalış süresi üzerine etkisini inceleyen randomize kontrollü çalışmaların çoğunda herhangi bir etki saptanmamıştır (20-26). Salgının başında düşük sayıda hasta içeren üç çalışmada ise etkili olduğu bildirilmiştir (27-29).

Farklı çalışmaların değerlendirildiği meta-analizlere bakıldığında çoğunda etkisiz olarak rapor edilmiştir (30-41). Temas sonrası profilakside de HQ etkisiz bulunmuştur $(42,43)$. FDA acil kullanım onayın $15 \mathrm{Ha}-$ ziran 2020'de iptal etmiş 1 Temmuz 2020'de kardiyak yan etkileri nedeniyle kullanımına karşı görüş bildirmiştir $(44,45)$.

Sonuç olarak in vitro etkinliği nedeniyle yeniden konumlandırılarak kullanılan HQ SARS-CoV-2'ye bağlı enfeksiyonda tedavi ve temas sonrası profilakside etkin görünmemektedir.

\section{Favipiravir}

Favipiravir influenza tedavisinde kullanılan bir antiviral ajandır (46). İlk olarak Wuhan'da kullanılmıştır. Ülkemizde de Sağlık Bakanlığı Rehberinde tedavide önerilen ilaçlardandır (2). Favipiravir başlıca Ebola ve influenza A'ya karşı antiviral etkinliği olan bir RNA polimeraz inhibitörüdür (46-49). İn vitro olarak SARSCoV-2'ye etkin olduğu rapor edilmiştir $(5,6,50,51)$.

Oral yolla kullanıldığında biyoyararlanımı \%95 civarında olan favipiravir başlıca böbrekler yoluyla elimine edilmektedir. Karaciğerde CYP2C8 enzimini bloke etmesi nedeniyle bu enzimle metabolize olan ilaçların 
serum düzeyinde artışa yol açabilmektedir (52). Karaciğer yetmezliği ve böbrek yetmezliği olan olgularda doz ayarlaması ile ilgili ek öneri bulunmamaktadır (53). Kullanım dozu genellikle 12 saatte bir $1600 \mathrm{mg}$ yükleme dozu sonrası 12 saatte bir $600 \mathrm{mg}$ şeklindedir. Ancak bu dozun SARS-CoV-2'yi inhibe etme açısından yetersiz olabileceği rapor edilmiștir (54). Tayvan'da 63 doğrulanmış COVID-19 olgusunun dahil edildiği bir çalışmada yükleme dozu $45 \mathrm{mg} / \mathrm{kg} / \mathrm{gün}$ dozunun altında ise yedinci gündeki klinik iyileşmenin olumsuz etkilendiği bildirilmiştir (55). Favipravirin en sık yan etkisi hiperürisemi olarak rapor edilmiştir (56). Diğer yan etkileri karaciğer enzimleri ve trigliserid düzeylerinde artış, anemi, lökopeni, nötropeni ve diyare şeklindedir. Gebelikte kullanımı önerilmez. Tedavinin bitmesinden itibaren bir hafta süreyle her iki cins için kontrasepsiyon önerilmektedir (57).

Favipiravirin semptomlar başladıktan sonraki 7 gün içinde uygulandığı açık etiketli, kontrollü bir çalışmada viral klirens zamanının daha kısa $(p=0.0026)$ ve bilgisayarlı tomografide düzelme oranının daha fazla olduğu ( $p=0.004$ ) bildirilmiştir (58). Kocayiğit ve arkadaşları tarafından yoğun bakım ünitesi (YBÜ) hastalarında yapılan bir diğer çalışmada favipiravir, lopinavir/ ritonavir ile karşılaştırılmış favipiravir tedavisi uygulanan hasta grubunda YBÜ'de yatış süresinin anlamlı derecede daha kısa olduğu rapor edilmiştir $(p=0.010)$ (59). Rusya'da yapılan çok merkezli, açık etiketli, randomize kontrollü bir çalışmada SARS-CoV-2 polimeraz zincir reaksiyonu (PZR) pozitif orta derecede pnömoni olgularına favipiravir uygulanmıştır. Beşinci günde viral klirens oranının kontrol grubuna göre daha fazla $(p=0.018)$, ateş düşme süresinin kontrol grubuna göre daha kısa $(p=0.007)$ olduğu bildirilmiştir. Aynı çalışmada 10. gün viral klirens ve 15 . gün $B T$ bulgularında düzelme açısından favipiravir grubuyla kontrol grubu arasında fark saptanmamıştır. Yan etki açısından her iki grup arasında fark olmadığı rapor edilmiştir (60). Chen ve arkadaşlarının yaptığı prospektif, randomize kontrollü, açık etiketli çalışmada 18 yaş üzerinde ve semptom başlangıcından itibaren 12 . günün içinde olan 116 vaka ile 120 kişiden oluşan kontrol grubu karşılaştırılmıştır. Çalışma sonuçlarına göre orta ciddiyette hastalığı olanlarda 7. gün klinik iyileşme oranı daha fazla $(p=0.0199)$, ateşin normale dönmesi ve öksürükte düzelme daha kısa sürede $(p<0.0001)$ olmuştur. Ancak oksijen desteği, MV intiyacı, YBÜ'ye kabul, mortalite ve tüm hastalar bir arada değerlendirildiğinde 7. günde klinik düzelme oranları açısından favipiravir tedavisi alan grupla kontrol grubu arasında anlamlı fark olmadığı bildirilmiştir. Aynı çalışmada favipiravir grubunda ürik asit düzeylerindeki artış kontrol grubuna göre daha fazla oranda (\%13.8 vs \%2.5) saptanmıştır (61).
Favipiravir viral klirensde gecikme olan (ortalama 61 gün) 8 olguya verilmiş, olguların 7'sinde 6 . gün viral klirens sağlandığı bildirilmiștir (62). Mekanik ventilasyon uygulanan 13 hastada yapılan prospektif bir çalışmada inflamatuvar yanıtın kısmen kontrol altına alındığı rapor edilmiştir (63).

Favipiravirin erken veya geç kullanımı Doi ve arkadaşları tarafından yapılan prospektif, randomize bir çalışmada araştırılmıştır. Çalışmaya 16 yaş üzerinde asemptomatik veya hafif COVID-19 olguları dahil edilmiştir. Otuz altı vakaya birinci gün, 33 vakaya 6 . gün favipiravir tedavisi verilmiştir. Altıncı gün viral klirensin erken tedavi başlanan grupta daha yüksek oranda (\%66.7 vs \% 56.1, HR: 1.416, \%95 GA: 0.764 - 2.623) olduğu bildirilmiştir (64). Lou ve arkadaşlarının yaptığı randomize kontrollü çalışmada favipiravir tedavisi alan 10 olgu darunavir/kobisistat veya arbidol+ inhale interferon- $\alpha$ alan hastalarla karşılaştııı Imış, 14. günde viral klirens ve klinik iyileşme süresi açısından gruplar arasında anlamlı fark olmadığı rapor edilmiştir (6).

Favipiravirin kullanıldığı ülkeler ittalya, Japonya, Rusya, Ukrayna, Özbekistan, Moldova, Kazakistan, Bangladeş, Mısır, Hindistan ve Türkiye'dir (54). Favipiravirin COVID-19 tedavisinde kullanımı ile ilgili daha fazla sayıda hasta içeren randomize kontrollü çalışmalara intiyaç vardır.

\section{Remdesivir}

Remdesivir adenozin nükleozid analoğudur. RNA bağımlı RNA polimeraz enzimi için substrat gibi davranarak zincirin sonlanmasına neden olur. İ vitro olarak SARS-CoV-2'ye etkin olduğu gösterilmiştir $(65,66)$ Doz ilk gün 200 mg IV yükleme dozunu takiben günde $100 \mathrm{mg}$ idame şeklindedir ve IV olarak kullanılmaktadır. Her doz 30-120 dakikada infüzyon şeklinde verilmelidir. Kullanım süresi MV ya da ekstrakorporeal membran oksijenizasyonu (ECMO)'da olmayan hastalar için 5 gün, 5 günde klinik iyileşme gözlenmeyen hastalar için 10 gün, MV veya ECMO uygulananlar için 10 gündür $(67,68)$.

Böbrek yetmezliği açısından eGFR $<30 \mathrm{~mL} /$ dakika olan hastalarda önerilmemektedir (69). Bilinen hipersensitivite reaksiyonu varsa kullanımı kontrendikedir. İnfüzyon ilişkili klinik reaksiyonlar hipotansiyon, bulantı, kusma, terleme ve titreme olarak bildirilmiștir. Ciddi yan etkileri ALT'de artış, karaciğer toksisitesi ve major sinus bradikardisi şeklindedir (68).

Amerika Ulusal Sağlık Enstitüsü (NIH) tarafından düzenlenmiş olan çift kör placebo kontrollü çalışmaya SARS-CoV-2 PZR pozitif ve oksijen saturasyonu $\% 94$ 'ün altında olan olgular dahil edilmiştir. Remde- 
sivir grubunda 541, plasebo grubunda 521 kişi yer almış 29. gün mortalitesi remdesivir ve plasebo gruplarında sırasıyla \%11.4 ve \%15.2 olarak saptanmıştır (HR:0.73; 0.52-1.03). Aynı çalışmada ortalama klinik iyileşme zamanı remdesivir grubunda daha kısa bulunmuştur (10 güne karşı 15 gün, $p<0.001,1.29 ; 1.12$ -1.49). İstenmeyen etkiler olarak glomeruler filtrasyon hızında azalma, Hb ve lenfosit sayısında düşme, respiratuar yetmezlik, anemi, ateş, hiperglisemi, kreatinin ve glukozda artış tespit edilmiştir (70). Wang ve arkadaşları tarafından yapılan ciddi COVID-19 olgularının dahil edildiği çift kör, randomize, plasebo kontrollü, çok merkezli bir çalışmada 158 olguya remdesivir, 79 olguya plasebo uygulanmış, kantitatif PZR ile üst solunum yolu ve alt solunum yolu örneklerinde viral yükün etkilenmediği gösterilmiştir. Aynı çalışmada klinik iyileşme süresi ve 28. gün mortalite oranları açısından gruplar arasında herhangi bir fark saptanmamıştır. İstenmeyen etkiler olarak konstipasyon, hipoalbüminemi, hipokalemi, anemi, trombositopeni ve total bilirubin artışı rapor edilmiştir (71)

Açık etiketli randomize kontrollü bir çalışma olan Solidarity çalışmasında hastanede yatan COVID-19 olgularından 2473'ü remdesivir 2708'i plasebo almış, mortalite açısından arada anlamlı fark olmadığı bildirilmiştir (19). Spinner ve arkadaşlarının çalışmasında remdesivir alan grup 5 gün ve 10 gün olmak üzere iki gruba ayrılmış, kontrol grubu ile remdesivir alan iki grup arasında mortalite açısından anlamlı fark olmadığı rapor edilmiştir (72). Aynı çalışmada 5 gün remdesivir alan grupta 11. günde klinik iyileşme oranı daha yüksek bulunmuş ( $p=0.02), 10$ gün alan grupta fark saptanmamıştır. Remdesivir, Avrupa illaç Kurumu (EMA) tarafından COVID-19 tedavisinde 25 Haziran 2020'de ilk onaylanan ilaç olmuştur (73). Discovery çalışmasının Avrupa ayağı olan EU-RESPONSE projesinde 776 hastanın 389'u remdesivir, 387'si standart bakım almış, iki hafta sonra tedavinin etkinliği değerlendirilmiş ve veri güvenliği izleme komitesi tarafından etkinliği ile ilgili bir kanıt olmadığından 27 Ocak 2021'de çalışmaya hasta dahil edilmesi durdurulmuştur (74).

Şubat 2021'de yayınlanan Amerika Enfeksiyon Hastalıkları Derneği (IDSA) rehberine göre remdesivir hastanede yatan ciddi COVID-19 hastalarında önerilmektedir. Stokların sınırlı olması da dikkate alınarak remdesivirin ekstrakorporal membran oksijenizasyonu (ECMO) ya da MV desteği alan olgulardan ziyade oksijen tedavisi alan ciddi COVID-19 hastalarında daha faydalı olabileceği değerlendirmesi yapılmıştır (75). DSÖ 20 Kasım 2020'de Solidarity çalışması ve üç diğer randomize kontrollü çalışma sonuçları dikkate alındığında remdesivir kullanımının mortalite, MV ihtiyacı ve iyileşme süresine etkisinin olmadığı gerekçesiyle remdesivir kullanımına karşı görüş yayınlamıştır (76). Sonuçta remdesivir konusunda da farklı öneriler bulunmaktadır.

\section{Monoklonal Antikorlar}

Monoklonal antikorlar içerisinde bamlanivimab (LYCoV555), bamlanivimab + etesevimab, carisimivab + imdevimab, gibi ilaçlar yer almaktadır. Bamlanivimab virüsün spike proteininin reseptör bağlayan kısmına bağlanan Ig G1 monoklonal antikordur. LY-CoV555 monoklonal antikoru organ yetmezliği olmayan COVID-19 tanılı hastanede yatan hastalarda remdesivirle birlikte kullanıldığında etkili bulunmamıştır (77). Birçok araştırmacı LY-CoV555'in hastalığın erken döneminde ayaktan hastalarda kullanılması görüşünü savunmaktadır. Gottlieb ve arkadaşları tarafından yürütülen randomize bir klinik çalışmada, bamlanivimab farklı dozlarda kullanılmış ve viral yükte belirgin azalma olmadığı belirlenmiştir (78). Chen ve arkadaşları tarafından ayaktan başvuran COVID-19 hastalarında yapılan bir çalışmada, LY-CoV555 alan grupta hastaneye yatış ve acil başvurusu \%1.6, plasebo grubunda \%6.3 olup aradaki fark istatistiksel olarak anlamlı bulunmamıştır (79). Gottlieb ve arkadaşları tarafından yapılan çalışmanın "post hoc analizinde" bamlanivimab 700 mg alan 65 yaş veya üzerinde veya vücut kitle indeksi 35 ya da daha fazla olan hastalarda hastaneye yatış oranı \%2.7, plasebo grubunda \%13.5 olarak bildirilmiştir. Ancak bamlanivimab alan hastalarda farklı dozlara göre \%7.1 ile \%11.3 arasında dirençli varyantların ortaya çıktığı, bu oranın plasebo grubunda \%4.8 olduğu rapor edilmiştir (78). IDSA ayaktan COVID-19 olgularında bamlanivimab tedavisinin rutin kullanımını önermemektedir. Hastaneye yatan ciddi COVID-19 hastalarında da bamlanivimab monoterapisine karşı görüş bildirmiştir. Amerika İlaç ve Gıda Kurumu (FDA) tarafından tanımlanan artmış risk olan olgularda bilgilendirilmiş onam alınarak kullanılabileceği belirtilmiştir (75).

Etesivimab da bamlanivimab gibi virüsün spike proteininin reseptör bağlayan kısmına bağlanan Ig G1 monoklonal antikordur. Bamlanivimab için erken kulIanım izni 10 Kasım 2020'de etesivimab için 9 Şubat 2021 'de verilmiştir (80). Bamlanivimab ve etesivimab kombinasyonu hafif ve orta şiddetteki COVID-19'da yüksek riskli ya da hastaneye yatış gereken olgularda acil onay almıştır. Acil kullanım onayında "yüksek risk" takip eden kriterlerden birinin olması olarak tanımlamıştır: Vücut kitle indeksi $\geq 35$; kronik böbrek hastalığı; diyabet; immünsupresif hastalık; yaş $\geq 65$, yaş $\geq 55$ olan hastada kardiyovasküler hastalık veya hipertansiyon veya $\mathrm{KOAH}$ ya da kronik respiratuvar hastalık varlığı (80). İkili tedavi 65 yaş veya üzeri ve 
VKi 35 ya da üzeri olan hasta grubunda viral yük ve hastaneye yatış üzerine etkili bulunmuştur. İkili tedavi alan olgularda dirençli varyantların plaseboya göre daha az oranda ortaya çıktığı bildirilmiştir (\%1'e karşı \%4.8). Ancak Güney Afrika ve Brezilya varyantlarına etkisiz olduğu rapor edilmiştir (81). Kombinasyonun aynı IV infüzyonun içinde eş zamanlı verilmesi önerilmektedir. Bamlanivimab 700 mg, etesivimab 1400 mg olarak kullanılmaktadır. Infüzyon zamanı kullanılan doza göre farklılık göstermektedir ve yavaş infüzyon önerilmektedir. Renal yetmezlik ve hafif hepatik yetmezlikte doz ayarı önerilmez. Yan etkiler infüzyon sırasında ve tamamlandıktan sonraki bir saat izlenmelidir. İnfüzyon ilişkili ateş, titreme, hipotansiyon, anjioödem, boğaz iritasyonu, ürtiker dahil raş, kaşıntı, myalji ve başdönmesi görülebilen yan etkiler arasındadır. Anafilaksi dahil ciddi hipersensitivite reaksiyonu görülebilir. Tedavinin mümkün olduğu kadar erken dönemde ideal olarak 5 günden önce başlaması önerilmektedir. Ancak 8-10 güne dek etkili olabilir (80).

Casirivimab ve imdevimab (Regeneron) spesifik olarak SARS-CoV-2 spike bölgesini bloke etmek üzere geliştirilmiş iki monoklonal antikordur. Ciddi hastalığa ilerleme ya da hastaneye yatma riski olan hafif ve orta şiddetteki COVID-19 hastalarında kullanılmak üzere 21 Kasım 2020'de FDA tarafından onay almıştır (82). Casirivimab 1200 mg ve imdevimab 1200 mg birlikte infüzyon şeklinde verilir. Böbrek yetmezliğinde doz ayarı yoktur. Karaciğer yetmezliği ile ilgili veri yoktur. Hasta yan etkiler açısından infüzyon süresince ve sonrasında bir saat izlenmelidir. İnfüzyon ilişkili olarak ateş, titreme, bulantı, başağrısı, bronkospazm, hipotansiyon, anjioödem, boğaz iritasyonu, ürtiker dahil raş, bulantı ve baş dönmesi görülebilir. Ciddi hipersensitivite reaksiyonları veya anafilaksi diğer yan etkileri arasındadır (82).

\section{Sonuç}

Pandeminin başından itibaren çok sayıda ilaç adayı COVID-19 tedavisinde denenmiştir. Bu ilaçlardan bir kısmı farklı endikasyonlarda onaylı olup yeniden konumlandırılarak kullanılmıştır. Mevcut bilgilerle SARS-CoV-2 virüsüne etkinliği yüksek kanıt düzeyiyle gösterilmiş antiviral bir ajan yoktur ancak tüm dünyada çalışmalar devam etmektedir. Monoklonal antikorlar umut vadetmekte olup bu konuda da bilimsel araştırmalar sürmektedir.

\section{Kaynaklar}

1. Fragkou PC, Belhadi D, Peiffer-Smadja N Moschopoulos CD, Lescure $\mathrm{FX}$, Janocha $\mathrm{H}$, et al. Review of trials currently testing treatment and prevention of COVID-19. CMI 2020;26(8):98898
2. T.C. Sağlık Bakanlığı Halk Sağıı̆ı Genel Müdürlüğü COVID-19 Erişkin Hasta Tedavisi. [Internet]. [cited 22 March 2021] Available from: https://covid19.saglik.gov.tr/Eklenti/39061/0/covid-19rehberieriskinhastatedavisipdf.pdf.

3. Siddigi J, Mehra MR. COVID-19 illness in native and immunosuppressed states: A clinical-therapeutic staging proposal. Heart Lung Transplant 2020;39(5):405-7.

4. Liu J, Chen H, Tang K, Guo Y. Clinical manifestations and outcome of SARS-CoV-2 infection during pregnancy. J Infect 2020 Mar 4. doi: 10.1016/j.jinf.2020.02.028

5. Wang M, Cao R, Zhang L, Yang X, Liu J, Xu M, et al. Remdesivir and chloroquine effectively inhibit the recently emerged novel coronavirus (2019-nCoV) in vitro. Cell Research 2020;30(3):269-71.

6. Lu CC, Chen MY Wan-Shin L, Chang YL. Potential therapeutic agents against COVID-19: What we know so far. J Chin Med Assoc 2020;83(6):534-6. doi: 10.1097/JCMA.0000000000000318

7. Yao X, Ye F, Zhang Z, Cui C, Huang B, Niu P, et al. In vitro antiviral activity and projection of optimized dosing design of hydroxychloroquine for the treatment of severe acute respiratory syndrome coronavirus 2 (SARS-CoV-2). Clin Infect Dis 2020;40:(5):416-37.

8. Barlow A, Landolf KM, Barlow B, Yeung SYA, Heavner JJ, Claassen CW, et al. Review of emerging pharmacotherapy for the reatment of coronavirus disease 2019. Pharmacotherapy 2020. doi: $10.1002 /$ phar.2398

9. Schrezenmeier E, Dörner T. Mechanisms of action of hydroxychloroquine and chloroquine: implications for rheumatology. Nat Rev Rheumatol 2020;16:155-66.

10. Nakayama T, Sugano Y, Yokokawa T, Nagai T, Matsuyama TA Ohta-Ogo K, et al. Clinical impact of the presence of macrophages in endomyocardial biopsies of patients with dilated cardiomyopathy. Eur J Heart Fail 2017;19(4):490-8

11. Hoffmann H, Mösbauer K, Hofmann-Winkler H, Kaul A, Kleine-Weber $\mathrm{H}$, Krüger $\mathrm{N}$, et al. Chloroquine does not inhibit infection of human lung cells with SARS-cov-2. Nature 2020;585(7826):588-90. https://doi.org/10.1038/s41586-0202575-3

12. Maisonnasse, P., Guedi J, Contreas V, Behillil S, Solas C, Marlin $\mathrm{R}$, et al. Hydroxychloroquineuse against SARS-cov-2 infection in non-human primates. Nature 2020;585(7826):584-7 https://doi.org/10.1038/ s41586-020-2558-4

13. Letter to Dr Rick Bright re: request for Emergency Use Authorization for use of chloroquine phosphate or hydroxychloroquine sulfate supplied from the strategic national stockpile for treatment of 2019 coronavirus disease. Published March 28, 2020. [Internet]. [cited 22 March 2021] Available from: https://www. fda.gov/media/136534/download

14. Tecen-Yücel K, Kara E, Demirkan K, Ünal S. Covid-19 tedavisinde hidroksiklorokin kullanımı. FLORA 2020;25(3):283-91.

15. Furst DE. Pharmacokinetics of hydroxychloroquine and chloroquine during treatment of rheumatic diseases. Lupus 1996;(Supp 1):S11-5.

16. Stokkermans TJ, Goyal A, Bansal P, Trichonas G. Chloroquine And Hydroxychloroquine Toxicity. Treasure Island (FL): StatPearls Publishing LLC, 2020.

17. Ferner RE, Aronson JK. Chloroquine and hydroxychloroquine in covid-19. BMJ 2020;369:m1432

18. RECOVERY Collaborative Group, Horby P, Mafham M, Linsell L, Bell JL, Staplin N, Emberson JR, et al. Effect of Hydroxychloroquine in Hospitalized Patients with COVID-19: Preliminary results from a multicentre, randomized, controlled trial. N Engl J Med. 2020 Nov 19;383(21):2030-2040. doi: 10.1056/NEJMoa2022926.

19. WHO Solidarity Trial Consortium, Pan H, Peto R, Henao-Restrepo AM, Preziosi MP, Sathiyamoorthy V, Abdool Karim Q, et al. Repurposed Antiviral Drugs for Covid-19 - Interim WHO Solidarity Trial Results N Engl J Med. 2021;384(6):497-511. doi: 10.1056/NEJMoa2023184. 
20. Cavalcanti AB, Zampieri FG, Rosa RG, Azevedo LCP, Veiga VC, Avezum A, et al. Hydroxychloroquine with or without Azithromycin in Mild-to-Moderate Covid-19. N Engl J Med. 2020;383(21):2041-2052. doi: 10.1056/NEJMoa2019014

21. Tang W, Cao Z, Han M, Wang Z, Chen J, et al. Hydroxychloroquine in patients with mainly mild to moderate coronavirus disease 2019: open label, randomised controlled trial BMJ. 2020 May 14;369:m1849. doi: 10.1136/bmj.m1849.

22. Abd-Elsalam S, Esmail ES, Khalaf M, Abdo EF, Mohammed A. Medhat MA, Abd El Ghafar MS, et al. Hydroxychloroquine in the Treatment of COVID-19: A Multicenter Randomized Controlled Study. Am J Trop Med Hyg. 2020103(4):1635-1639. doi: 10.4269/ajtmh.20-0873.

23. Skipper CP, Pastick KA, Engen NW, Bangdiwala AS, Abassi M, Lofgren SM, et al. Hydroxychloroquine in Nonhospitalized Adults With Early COVID-19: A Randomized Trial. Ann Intern Med. 2020;173(8):623-631. doi: 10.7326/M20-4207.

24. Self WH, Semler MW, Leither LM, Casey JD, Angus DC, Brower RG. Effect of Hydroxychloroquine on Clinical Status at 14 Days in Hospitalized Patients With COVID-19 A Randomized Clinical Trial. JAMA. 2020;324(21):2165-2176. doi:10.1001/ jama.2020.22240

25. Lyngbakken MN, Berdal JE, Eskesen A, Kvale D, Olsen IC, Rueegg CS. A pragmatic randomized controlled trial reports lack of efficacy of hydroxychloroquine on coronavirus disease 2019 viral kinetics. Nat Commun 2020;11(5284) https://doi. org/10.1038/s41467-020-19056-6

26. Mitjà $\mathrm{O}$, Corbacho-Monné $\mathrm{M}$, Ubals $\mathrm{M}$, Tebe $\mathrm{C}$, Peñafiel $\mathrm{J}$, Tobias a, et al. Hydroxychloroquine for Early Treatment of Adults with Mild Covid-19: A Randomized-Controlled Trial. Clinical In fectious Diseases 2020; https://doi.org/10.1093/cid/ciaa100929

27. Chen Z, Hu J, Zhang Z, Jiang S, Han S et al. Efficacy of hydrochlroquine in patients with COVID-19: Results of a randomized trial; 2020: https://www.medrxiv.org/content/10.1101/2020.03.2 $2.20040758 \mathrm{v} 2$

28. Huang M, Tang T, Pang P, Li M, Ma R, Lu J, et al. Treating COVID-19 with Chloroquine. J Mol Cell Biol. 2020;12(4):322-325. doi: 10.1093/jmcb/mjaa014.

29. Chen L, Zhang ZY, Fu JG, Feng ZP, Zhang SZ, Han QY, et al. Efficacy and safety of chloroquine or hydroxychloroquine in moderate type of COVID-19: a prospective open-label randomized controlled study. Medrxiv preprint doi: https://doi.or$\mathrm{g} / 10.1101 / 2020.06 .19 .20136093 . t$

30. Mega TA, Feyissa TM, Bosho DD, Goro KK, Negera GZ. The Outcome of Hydroxychloroquine in Patients Treated for COVID-19: Systematic Review and Meta-Analysis. Can Respir J 2020;4312519. doi: 10.1155/2020/4312519.

31. Chandrasekar VT, Venkatesalu B, Patel HK, Spadaccini M, Jacob Manteuffel J, et al. Systematic review and meta-analysis of effectiveness of treatment options against SARS-CoV-2 infection J Med Virol. 2021;93(2):775-785. doi: 10.1002/jmv.26302.

32. Das RR, Behera B, Mishra B, Naik SS. Effect of Chloroquine and Hydroxychloroquine on COVID-19 Virological Outcomes: An Updated Meta-Analysis. Indian J Med Microbio 2020;38:265-76.

33. Das S, Bhowmick S, Tiwari S, Sen S. An Updated Systematic Review of the Therapeutic Role of Hydroxychloroquine in Coronavirus Disease-19 (COVID-19). Clin Drug Investig. 2020 (7):591-601. doi: 10.1007/s40261-020-00927-1

34. Elavarasi A, Prasad M, Seth T, Sahoo RK, Madan K, Nischal N, et al. Chloroquine and Hydroxychloroquine for the Treatment of COVID-19: a Systematic Review and Meta-analysis. J Gen Intern Med 35(11):3308-14 DOI: 10.1007/s11606-020-06146-w

35. Maraolo AE, Grossi A. Safety of hydroxychloroquine for treatment or prevention of SARS-CoV-2 infection: A rapid systematic review and meta-analysis of randomized clinical trials. Immun Inflamm Dis. 2021;9(1):31-6. doi: 10.1002/iid3.374.

36. Hong TS, Gonzalez J, Nahass RG, Brunetti L. Impact of Hydroxychloroquine on Mortality in Hospitalized Patients with
COVID-19: Systematic Review and Meta-Analysis. Pharmacy 2020;8(4):208. doi: 10.3390/pharmacy8040208.

37. Pathak SK, Salunke AA, Thivari P, Pandey A, Nandy K, Ratna HVK, et al. No benefit of hydroxychloroquine in COVID-19: Results of Systematic Review and Meta-Analysis of Randomized Controlled Trials Diabetes Metab Syndr. 2020;14(6):1673-80. doi: 10.1016/j.dsx.2020.08.033.

38. Shamshirian A, Hessami A, Heydari K, Alizadeh-Navaei R, Ebrahimzadeh MA, Yip GW, et al. The Role of Hydroxychloroquine in COVID-19 Treatment: A Systematic Review and Meta-Analysis. Ann Acad Med Singap 2020;49:789-800 DOI: 10.47102/annals-acadmedsg.2020370

39. Singh AK, Singh A, Singh R, Misra A. Hydroxychloroquine in patients with COVID-19: A Systematic Review and meta-analysis. Diabetes Metab Syndr 2020;14:589-96

40. Ullah W, Abdullah HM, Roomi S, Sattar Y, Almas T,Gowda $\mathrm{SN}$,et al. Safety and Efficacy of Hydroxychloroquine in COVID-19: A Systematic Review and Meta-Analysis. J Clin Med Res. 2020;12(8):483-491. doi: 10.14740/jocmr4233.2(8

41. Zang Y, Han X, He M, Shi J, Li Y. Hydroxychloroquine use and progression or prognosis of COVID-19:a systematic review and meta-analysis. Naunyn Schmiedebergs Arch Pharmacol. 2020:1-8. doi: 10.1007/s00210-020-01964-5. 483-491

42. Boulware DR, Pullen MF, Bangdiwala AS, Pastick KA, Lofgren SM, Okafor EC, et al. A Randomized Trial of Hydroxychloroquine as Postexposure Prophylaxis for Covid-19. N Eng J Med 2020;383:517-25.

43. Mitjà $O$, Corbacho-Monné $M$, Ubals $M$, Alemany $A$, Suñer $C$, Tebe C, et al. A Cluster-Randomized Trial of Hydroxychloroquine for Prevention of Covid-19. N Engl J Med 2021;384:417-27. DOI: 10.1056/NEJMoa2021801

44. Coronavirus (COVID-19) Update: FDA Revokes Emergency Use Authorization for Chloroquine and Hydroxychloroquine [Internet] [cited 20 March 2021]. Available from: https://www. fda.gov/media/138945/download

45. FDA cautions against use of hydroxychloroquine or chloroquine for COVID-19 outside of the hospital setting or a clinical trial due to risk of heart rhythm problems. [Internet] [cited 20 March 2021]. Available from: https://www.fda.gov/drugs/drug-safety-and-availability/fda-cautions-against-use-hydroxychloroquine-or-chloroquine-covid-19-outside-hospital-setting-or

46. Furuta Y, Gowen BB, Takahashi K, Shiraki K, Smee DF, Barnard DL. Favipiravir (T-705), a novel viral RNA polymerase inhibitor. Antiviral Res. 2013;100(2):446-54.

47. Oestereich L, Lüdtke A, Wurr S, Rieger T, Muñoz-Fontela C, Günther S. Successful treatment of advanced Ebola virus infection with T-705 (favipiravir) in a small animal model. Antiviral Res. 2014;105:17-21.

48. Sissoko D, Laouenan C, Folkesson E, M'Lebing AB, Beavogui $\mathrm{AH}$, Baize $\mathrm{S}$, et al. Experimental treatment with favipiravir for Ebola Virus Disease (the JIKI Trial): A historically controlled, single-arm proof-of-concept trial in Guinea. PLoS Med. 2016;13(3):e1001967.

49. Bouazza N, Treluyer J-M, Foissac F, Mentré F, Taburet A-M, Guedj J, et al. Favipiravir for children with Ebola. The Lancet. 2015;385(9968):603-4.

50. Choy KT. Wong AY, Kaewpreedee P, Sia SF, Chen D Pui K, et al. Remdesivir, lopinavir, emetine, and homoharringtonine inhibit SARS-cov-2 replication in vitro. Antiviral Research 2020;178:104786. Doi: 10.1016/j.antiviral.2020.104786

51. Shannon, A., Selisko, B., Le, N.T.T, Huchting, J., Touret, F., Piorkowski, G., et al.,(2020) Favipiravir strikes the SARScov-2 at its Achilles heel, the RNA polymerase Nat Commun. 2020;11(1):4682. doi: 10.1038/s41467-020-18463-z.

52. Toyama Chemicals. Summary of Product Characteristics of Avigan. [Internet] [cited 17 Dec 2020]. Available from: https:// www.cdc.gov.tw/File/Get/ht8jUiB Ml-aKnlwstwzvw,

53. Madelain V, Nguyen TH, Olivo A, de Lamballerie X, Guedj J, Taburet AM, et al. Ebola 345 Virus infection: Review of the phar- 
macokinetic and pharmacodynamic properties of drugs considered for testing in human efficacy trials. Clin Pharmacokinet. 2016;55(8):907-23.

54. Kaya E, İnkaya AÇ, Demirkan K, Ünal S. COVID-19 Tedavisinde Favipiravir Kullanımı. FLORA 2021;26(1):1-11. doi: 10.5578/ flora.20219901

55. Rattanaumpawan P, Jirajariyavej S, Lerdlamyong K, Palavutitotai N, Saiyarin J. Real-world Experience with Favipiravir for Treatment of COVID-19 in Thailand: Results from a Multi-center Observational Study. Medrxiv preprint doi: https://doi.org/10 $.1101 / 2020.06 .24 .201332492020$

56. Kumagai Y, Murakawa Y, Hasunuma T, Aso M, Yuji W, Sakurai $\mathrm{T}$, et al. Lack of effect of favipiravir, a novel antiviral agent, on QT interval in healthy Japanese adults. Int $\mathrm{J}$ Clin Pharmacol Ther. 2015;53(10):866-74.

57. Pharmaceuticals and Medical Devices Agency. Report on the Deliberation Results Avigan, Japan. Evaluation and Licensing Division, Pharmaceutical and Food Safety Bureau. [Internet] [cited 17 Dec 2020]. Available from: www.pmda.go.jp/ files/000210319.pdf.

58. Cai Q, Yang M, Liu D, Chen J, Shu D, Xia J, et al. Experimental treatment with favipiravir for COVID-19: An open-label control study. Engineering (Beijing). 2020;6(10):1192-8.

59. Kocayiğit H, Özmen Süner K, Tomak Y, Demir G, Yaylacı S Dheir $\mathrm{H}$, et al. Observational study of the effects of Favipiravi vs Lopinavir/Ritonavir on clinical outcomes in critically III patients with COVID-19. J Clin Pharm Ther. 2021;46(2):454-459. doi: $10.1111 /$ jcpt.13305

60. Ivashchenko AA, Dmitriev KA, Vostokova NV, Azarova VN, Blinow AA, Egorova AN, et al. AVIFAVIR for Treatment of Patients with Moderate COVID-19: Interim Results of a Phase II/ III Multicenter Randomized Clinical Trial. Clin Infect Dis 2020; ciaa1176. doi: 10.1093/cid/ciaa1176

61. Chen C, Huang J, Cheng Z, Zhang Y, Cheng Z et al. (2020). Favipiravir versus arbidol for COVID-19: a randomized clinical trial [online]. Medrxiv preprint doi:https://doi org/10.1101/2020.03.17.20037432

62. Fu D, Cao R, Zhao L, Li W, Zhong W, Wen J. Oral favipiravir for patients with delayed SARS-CoV-2 viral RNA clearance: a case series. Critical Care. 2020;24(1):578.

63. Yamamura $\mathrm{H}$, Matsuura $\mathrm{H}$, Nakagawa J, Fukuoka $\mathrm{H}$, Domi $\mathrm{H}$, Chujoh S. Effect of favipiravir and an anti-inflammatory strategy for COVID-19. Critical Care 2020;24(1):413.

64. Doi Y, Hibino M, Hase R, Yamamoto M, Kasamatsu Y, Hirose M, et al. A prospective, randomized, open-label trial of early versus late favipiravir in hospitalized patients with COVID-19. Antimicrobial Agents and Chemotherapy. 2020;64(12):e01897-20.

65. Agostini ML, Andres EL, Sims AC, Graham RL Sheahan TP, Lu $X$, et al. Coronavirus Susceptibility to the Antiviral Remdesivir (GS-5734) Is Mediated by the Viral Polymerase and the Proofreading Exoribonuclease. mBio 2018;9(2):e00221-18; DOI: 10.1128/mBio.00221-18

66. Williamson BN, Feldmann F, Schwarz B, Meade-White K, Porter DP, Schulz J, et al. Clinical benefit of remdesivir in rhesus macaques infected with SARS-CoV-2. Nature 2020;585 273-6. https://doi.org/10.1038/s41586-020-2423-5

67. National Health Institute COVID-19 Treatment Guidelines. [Internet] [cited 22 March 2021]. Available from: www.pmda.go.jp/ files/000210319.pdf.

68. The Sanford Guide to Antimicrobial Therapy 2021 App Version 4.2.15. Gilbert DN, Chambers HF, Saag, MS., Pavia, AT, Black D, Boucher H, Freedman DO, Kim K, Schwarz BS (Editors) Last content update: 24 Mar 2021.

69. Adamsick ML, Gandhi RG, Bidell MR, Elshaboury RH, Bhattacharyya RP, Kim AY. Remdesivir in Patients with Acute or Chronic Kidney Disease and COVID-19. J Am Soc Nephrol. 2020;(7):1384-6. doi: 10.1681/ASN.2020050589.

70. Beigel JH, Tomashek KM, Dodd LE, Mehta AK, Zingman BS, Kalil AC, et al. Remdesivir for the Treatment of Covid-19 -
Final Report N Engl J Med 2020;383:1813-26 doi: 10.1056/ NEJMoa2007764

71. Wang Y, Zhang D, Du G, Du R, Zhao J, Jin Y, et al. Remdesivir in adults with severe COVID-19: a randomised, double-blind, placebo-controlled, multicentre trial Lancet. 2020;395(10236):156978. doi: 10.1016/S0140-6736(20)31022-9.

72. Spinner CD, Gottlieb RL, Criner GJ, Lopez JRA, Cattelan AM, Viladomiu AS, et al. Effect of Remdesivir vs Standard Care on Clinical Status at 11 Days in Patient With Moderate COVID-19 A Randomized Clinical Trial. JAMA. 2020;324(11):1048-57. doi: 10.1001/jama.2020.16349.

73. European Medicines Agency. First COVID-19 treatment recommended for EU authorisation [Internet] [cited 22 March 2021]. Available from https://www.ema.europa.eu/en/documents/ press-release/first-covid-19-treatment recommended-eu-authorisation_en.pdf

74. Discovery Stops Testing Remdesivir Against Covid-19 For Lack Of Evidence Of Its Efficacy. [Internet] [cited 22 March 2021]. Available from: Https://Presse.Inserm.Fr/En/Discovery-Stops-Testing-Remdesivir-Against-Covid-19-For-Lack-Of-Evidence-Of-Its-Efficacy/42034/

75. Bhimraj A, Morgan RL, Shumaker AH, Lavergne V, Baden L, Cheng VC, et al. Infectious Diseases Society of America 2021; Version 4.1.1. [Internet] [cited 20 March 2021]. Available from: https://www.idsociety.org/practice-guideline/covid-19-guideline-treatment-and-management/.

76. WHO recommends against the use of remdesivir in COVID-19 patients [Internet] [cited 22 March 2021] Available from: https:// www.who.int/news-room/feature-stories/detail/who-recommends-against-the-use-of-remdesivir-in-covid-19-patients

77. ACTIV-3/TICO LY-CoV555 Study Group, Lundgren JD, Grund B, Barkauskas CE, Holland TL, Gottlieb RL, Sandkovsky U, et al. A Neutralizing Monoclonal Antibody for Hospitalized Patients with Covid-19. N Engl J Med 2021;384:905-14. doi: 10.1056/NEJMoa2033130.

78. Gottlieb RL, Nirula A, Chen P, Boscia J, Heller B, Morris J, et al. Effect of Bamlanivimab as Monotherapy or in Combination with Etesevimab on Viral Load in Patients With Mild to Moderate COVID-19 A Randomized Clinical Trial. JAMA. 2021;325(7):632-644. doi:10.1001/jama.2021.0202

79. Chen P, Nirula A, Heller B, Gottlieb RL, Boscia J, Morris J, et al. SARS-CoV-2 Neutralizing Antibody LY-CoV555 in Outpatients with Covid-19. N Engl J Med 2021; 384:229-237. DOI: 10.1056/ NEJMoa2029849

80. U.S. Food and Drug Administration. Fact Sheet for Health Care Providers: Emergency Use Authorization (EUA) of Bamlanivimab and Etesevimab. [Internet] [cited 22 March 2021] Available from: https://www.fda.gov/media/145802/download.

81. Wang P, Wang M, Yu J, Cerutti G, Nair MS, Huang Y, et al. Increased Resistance of SARS-CoV-2 Variant P.1 to Antibody Neutralization bioRxiv 2021.03.01.433466; doi: https://doi. org/10.1101/2021.03.01.433466

82. U.S. Food And Drug Administration Fact Sheet For Health Care Providers: Emergency Use Authorızatıon (Eua) Of Casırıvımab And Imdevımab. [Internet] [cited 22 March 2021] Available from: https://www.fda.gov/media/143892/download. 